Original Research Paper

\title{
Teaching Programming Using the Robot-Based Learning Approach
}

\section{Stephanus Mberema Kangungu ${ }^{1}$, Maizatul Hayati Mohamad Yatim ${ }^{1}$}

${ }^{1}$ Universiti Pendidikan Sultan Idris, Malaysia.

Article History

Received:

01.10 .2020

Revised:

18.10.2020

Accepted:

20.11.2020

*Corresponding Author:

Maizatul Hayati Mohamad Yatim Email:

maizatul@fskik.upsi.edu.com

This is an open access article, licensed under: $C C-B Y-S A$

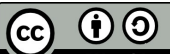

Abstract: This paper discusses learning theories, STEM, educational robotics as well as the current generation of students found in classrooms by reviewing previous and current academic literature on these topics, to assist in ascertaining the current advancements and theories related to the Robotbased learning approach as well as how these advancements have helped improve this approach and enabled educators to better make use of it. Furthermore, this paper reviews previous academic literature on computer programming to discuss the current learning approaches in use and the kind of learning tools being utilized. Once this topics are reviewed the reader can have a clear picture of the learning approach, what learning theory does it belong too, the type of students found in the classroom as well as what motivates them and the subject that is being taught as well as the different learning tools for this subject. The reader will also learn why improving the effectiveness of how programming is learned helps create more students good in STEM and how it assists in realising the Malaysian Educational Development Plan.

Keywords: Active Learning Theory, Computer Programming, Constructivism, Eduactional Robotics, STEM. 


\section{Introduction}

With the "flattening" of the global economy in the 21st century, the teaching of Science, Technology, Engineering, and Mathematics (STEM) has taken on new importance as economic competition has become truly global [1]. According to Fadzil and Saat [2] emphasis has been placed on the importance of science and the affective teaching and learning of it in schools in order to help Malaysia attain its aspirations of being fully developed and industrialized by the year 2020 .

Programming is one of the subsets of STEM and teaching programming to school students is challenging as different concepts have to be conveyed to the learners, who most of the time do not understand why the concepts have certain rules [3].

With all the different problems that have been hindering the teaching and learning of programming, stakeholders in education have tried different teaching approaches with an intent of finding the best. Zhang, Zhang, Stafford and Zhang [4] divided the teaching and learning approach into two categories: Traditional teaching approach and Active Learning Approach. Where the traditional teaching approach is teacher centred while the active learning approach uses exercises and peer learning combined with mini-lectures where necessary, as compared to the traditional extended lecture approach. Robot-based learning approach is an emerging learning approach and also a subset of the active learning approach.

The motivation behind the research to be carried out is based on current ongoing issues experienced during the teaching and learning of programming such as, young talents leaving because of the inappropriate approaches used to teach the subject [3]. Mahdin et al [3] further state that learning computer need to be revolutionize to cater for the needs of this iPad generation, also that programming is not as hard as many think unless learners are introduced to it incorrectly which results in them losing interest.

The academic literature reviewed for this paper was selected by first choosing papers that were published from the 2014 and onwards, second papers published in Malaysia or South East Asia and if there were few or no publications from this region then international papers were selected. Finally priority was given to papers that had a focus group of university students, primarily diploma students.

\section{Literature Review}

\subsection{STEM}

Gonzalez \& Kuenzi as cited in Kennedy \& Odell [1] define STEM education as a term that refers to teaching and learning in the fields of science, technology, engineering, and mathematics; typically including educational activities across all grade levels, from pre-school to post doctorate, and in both formal and informal classroom settings.

The STEM initiative outlined in the Malaysian education blueprint 2013-2025 (preschool to postsecondary education) has two aims; firstly to prepare students with the skills to meet the science and technology challenges and lastly "to ensure that Malaysia has a sufficient number of qualified STEM graduates [5].

Furthermore, Osman \& Saat [6] said the acquisition of STEM core competencies will gradually nourish the students to be critical and creative thinkers, uplift their scientific literacy, and more importantly stimulate themselves to be creative innovators. Also, the Malaysian ministry of education clearly outlines in the Malaysian education blueprint 2015-2025 (higher education) that it aspires to produce students who" have mastery of own disciplines, are able to harness, connect and apply knowledge learnt, and have an appreciation of culture, arts, and science, technology, engineering and Mathematics (STEM) [7].

It is believed that the main reason why STEM education has been an area of great interest in Malaysia is because a successful STEM education equips students with STEM core competencies in sequences that are built upon one another and can be applied within the context of real world application [6].

\subsection{Computer Programming}

Computer programming is the process of writing instructions that get executed by computers. The instructions, also known as code, are written in a programming language which the computer can understand and use to perform a task or solve a problem [8].

Computer programming languages allow us to give instructions to a computer in a language the computer understands. Just as many human-based languages exist, there are an array of computer 
programming languages that programmers can use to communicate with a computer [9]. There are a lot of different programming languages being used in the industry, Figure 1 is a list of the 10 most popular programming languages in 2018.

Computer programming is a subset of STEM which makes it a subject of interest in Malaysia especially in the education sector, as it falls under both engineering and information technology. Furthermore, there are many emerging applications that can be used by the students to learn computer science, robotics programming, and drag and drop blocks [10]. Kalelioglu [10] further states that the process of teaching computer programming to students is a difficult subject area. In older-age students, they lack logical reasoning and algorithmic thinking, and may have problems in programming courses. Programming processes can effectively be learned by using different instructional tools and techniques. Given that computer programming is becoming more popular in schools and after-school programs [11].

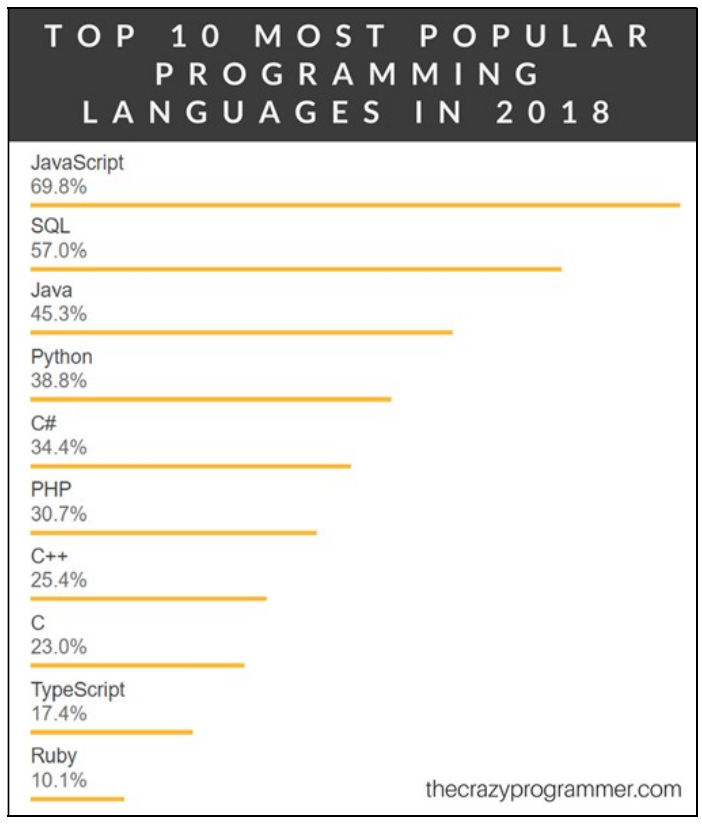

Figure 1. 10 Most Popular Programming Languages in 2018

\subsection{Generation}

As digital technologies form an inextricable part of young people's everyday lives, some commentators claim that the current generation of learners think and learn differently from their predecessors [12].

The different types of generations and their defining characteristics are shown in Figure 2 according to the Mccrindle website. The current generation is alpha and most of the students in the classrooms are either generation alpha or generation $\mathrm{z}$. The term generation alpha according to Tootell et al. [13] is being used to describe those being born at the cross-over of Generation $\mathrm{Z}$ and the new age.

According to the Mccrindle website generation alpha is composed of people born from the year 2010 onwards and generation $\mathrm{z}$ is composed of people born between the years 1995 and 2009. One of the characteristics of these two generations is that they are influenced by forums and robots as opposed to the generation of builders that is influenced by officials. Also their preferred learning styles are multi-modal and virtual, their ideal type of leaders are collaborators and co-creators and lastly their ideal leadership style is empowering or inspiring. 


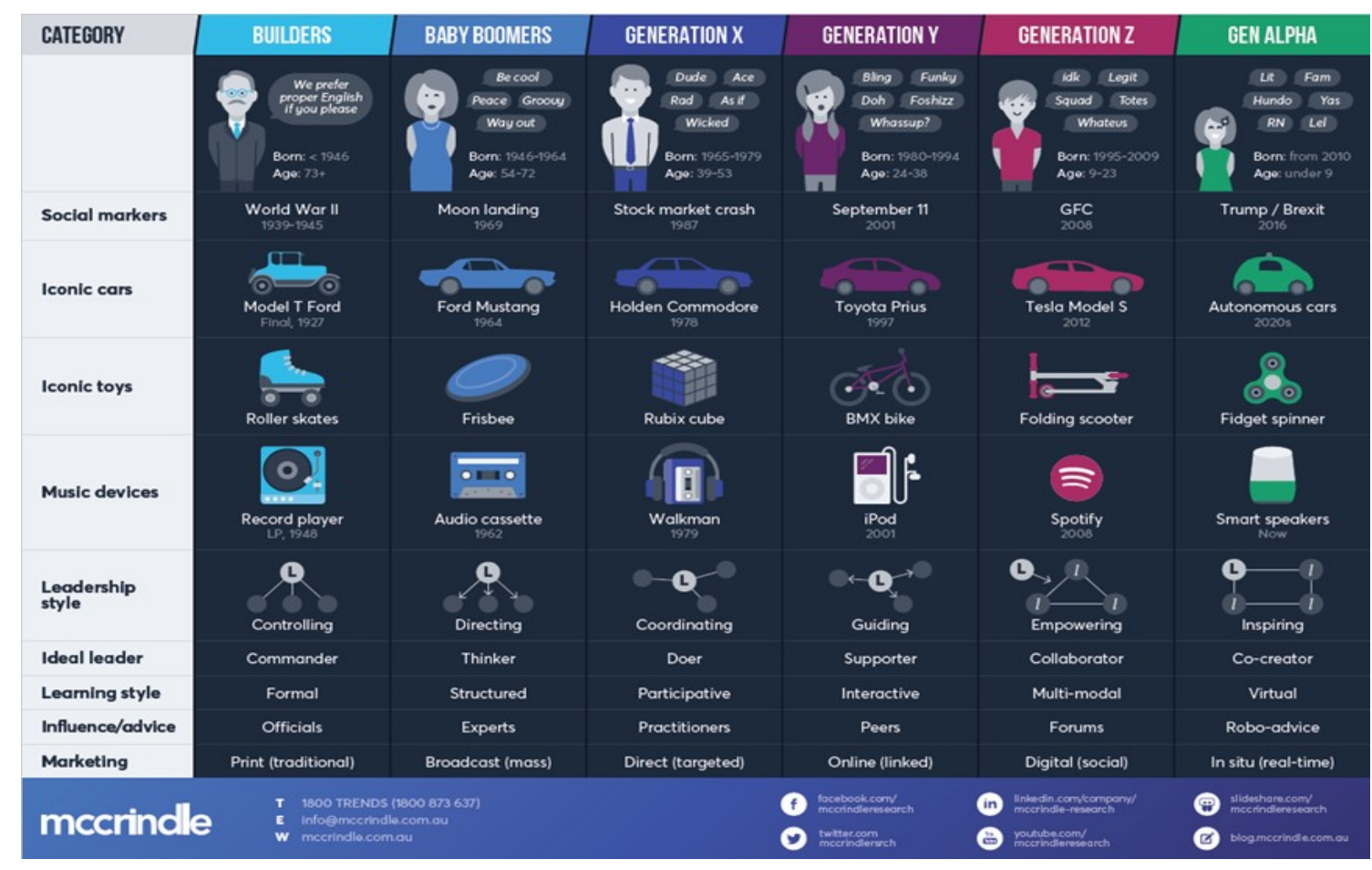

Figure 2. The Different Generations According to Mccrindle

In brief, the generation gap clearly shows that all the different age groups have different characteristics and in order for educators and researcher to find and plan lessons that will facilitate effective learning, they have to take notice all this characteristics when setting up lesson plans. Because it is evident that not only are the learning styles different for each generation, the influencing, leadership and motivational factors differ as well.

\subsection{Constructivism}

In the classroom, the constructivist view of learning can point towards a number of different teaching practices [14] which generally means teachers encourage students to build their own knowledge by experimenting and solving real world problems by using what they have learnt in the classroom [14].

Afterwards students can reflect about what they did and how it has modified their understanding of the situation or a certain concept. Piaget discusses that children go through stages in which they accept ideas they may later change or not accept.

Therefore, understanding is built up step by step through active participation and involvement of the learners cannot be considered as passive in any of the stages of development [14]. Simply put constructivism is learning by doing, reflection and discussion to form new ideas.

\subsection{Active Learning Approach}

Bonwell and Eison [15] define active learning as anything that involves students in doing things and thinking about the things they are doing. The activities vary but require students to do higher order thinking [16].

Active learning classrooms (ALCs) provide opportunities for increased student engagement and interaction with classmates and the instructor. Active learning approaches also often embrace the use of cooperative learning groups, a constructivist-based practice that places particular emphasis on the contribution that social interaction can make [16].

Brame [16] further states that "In addition to the evidence that active learning approaches promote learning for all students, there is some evidence that active learning approaches are an effective tool in making classrooms more inclusive". 


\subsection{Robot}

The adoption of educational robots in schools is a potential key contribution to education, but is limited by several factors: Price, integration within the existing curriculum and disciplines [17].

On the other hand, Research in the area of robotics has made available numerous possibilities for further innovation in the education of children, especially in the rehabilitation of those with learning difficulties and/or intellectual disabilities [18]. But Despite the scientific success and increasing evidence and applications, it seems that the majority of people is still sceptical or even against the application of robots in real contexts like education and care of children [18].

Conti et al. [18] further argue that this negative attitude is one of the biggest challenges that scientific research must address to be successful in giving real benefits in the field of education. Since public perception of an emerging scientific and technological product is important for the acceptance of such a product [18]. If used correctly the robots can help improve and develop students' robotics skills [19]; problem solving skills; creativity; innovativeness; motivation and capture their attention during lessons. Some of the robots currently being used in education are robots based on Arduino and Arduino UNO; LEGO Mindstorms NXT; Boe-Bot; printbots; NAO; Tiro; Pepper; IROBI and Robovie to mention a few.

\subsection{Robot-Based Learning Approach}

The term Educational Robotics (ER) to refer to the use of robots in education, however the current definition of ER is still vague and open to misinterpretation [20]. Despite all benefits of robotics, its incorrect use may be counterproductive. Therefore, the incremental use of the term ER is meaningless if it is not used correctly. Consequently, a concrete and precise definition of ER is required to support the development of it [20].

Angel-Fernandez and Vincze [20] define ER as a field of study that aims to improve learning experience of people through the creation, implementation, improvement and validation of pedagogical activities, tools (guidelines and templates) and technologies, where robots play an active role and pedagogical methods inform each decision. Studies have revealed that educational robots can communicate effectively and enhance student enjoyment and engagement in classrooms [21] and Papert showed that children can learn new skills by designing and assembling their own physical robots; moreover, robotics related activities offer considerable potential for improving classroom instruction [21].

The most used platforms in technology, programming and robotics learning in secondary schools are LEGO Mindstorms and Arduino. The LEGO Mindstorms platform consists of a programmable controller, engines, sensors and construction parts designed to fit together.

The main purpose of the LEGO Mindstorms Project was to create a motivating learning environment which allows "learning-by-doing". Papert created this catchy phrase to represent the idea of Constructionism. Whereas Arduino arose in the year 2005, in Italy as a project to have a hardware platform that can be easily programmed and used by people with no technical profile. Arduino and LEGO Mindstorms are two platforms which can make people come closer to robotics in an easy and simple way.

\section{Conclusion}

In conclusion, even though Robot-based learning is an emerging learning approach and still in its infancy stage the little research that has been carried out in regards to it shows that if it is properly put into practice it can positively increase the students motivation and they academic performance. Using it to teach programming students assists Malaysia in achieving international standard and meeting national development needs according to the Malaysian education blueprint 2013-2025 (preschool to post-secondary education).

In order to prepare students with the skills to meet the science and technology challenges and to ensure that Malaysia has a sufficient number of qualified STEM graduates. Also, the Malaysian ministry of education clearly outlines in the Malaysian education blueprint 2015-2025 (higher education) that it aspires to produce students who" have mastery of own disciplines, are able to harness, connect and apply knowledge learnt, and have an appreciation of culture, arts, and science, technology, engineering and Mathematics (STEM). Using RBL to teach programmer assists in all of this, as it directly fosters the development of two fields of STEM namely technology and engineering. 


\section{References}

[1] T. J. Kennedy, and M. R. L. Odell, "Engaging Students in STEM Education," Science Education International, vol. 25, no. 3, pp. 246-258, 2014.

[2] H. M. Fadzil, and R. M. Saat, "Enhancing STEM education during school transition: Bridging the gap in science manipulative skills," Eurasia Journal of Mathematics, Science and Technology Education, vol. 10, no. 3, pp. 209-218, 2014.

[3] H. Mahdin, N. Senan, S. Kasim, N. Ibrahim, and N. A. Abdullah, "Teaching computer programming to ipad generation," ARPN Journal of Engineering and Applied Sciences, vol. 11, no. 24, pp. 14082-14084, 2016.

[4] X. Zhang, C. Zhang, T. Stafford, and P. Zhang, "Teaching introductory programming to IS students : The impact of teaching approaches on learning performance," Journal of Information Systems Education, vol. 00424, no. 2, pp.147-156, 2013.

[5] Ministry of Education Malaysia, STEM Education: Policies And Prospects Toward Achieving International Standard And Meeting National Development Needs, 2018. [Online]. Available: https://www.akademisains.gov.my/download/STEM\%20Education_Dr\%20Azian.pdf. [Accessed: June 2020].

[6] K. Osman, and R. M. Saat, "University of M. Editorial," Science Technology, Engineering and Mathematics (STEM) education in Malaysia, vol.10, no. 3, pp. 153-154, 2014.

[7] Ministry of Education Malaysia, "Executive Summary Malaysia Education Blueprint 20152025 (Higher Education)," 2018. [Online]. Available: https://www.um.edu.my/ docs/defaultsource/about-um_document/media-centre/um-magazine/4-executive-summary-pppm-20152025.pdf?sfvrsn=4. [Accessed: July 2020].

[8] Anonymous, "Computer Programming Courses, (n.d.)," [Online]. Available: https://www.edx.org/learn/ computer-programming. [Accessed: June 2020].

[9] Anonymous, "Computer Programming Languages, (n.d.)," [Online]. Available: https://www.computer science.org/resources/computer-programming-languages/. [Accessed: June 2020].

[10] F. Kalelioglu, "A new way of teaching programming skills to K-12 students: Code.org," Computers in Human Behavior, vol. 52, pp. 200-210, 2015.

[11] Blikstein, P., Worsley, M., Piech, C., Sahami, M., Cooper, S., \& Koller, D, "Programming Pluralism: Using Learning Analytics to Detect Patterns in the Learning of Computer Programming," Journal of the Learning Sciences, vol. 23, no. 4, pp. 561-599, 2014.

[12] K. W. Lai, and K. S. Hong, "Technology use and learning characteristics of students in higher education: Do generational differences exist?," British Journal of Educational Technology, vol. 46, no. 4, pp. 725-738, 2015.

[13] H.Tootell, M. Freeman, and A. Freeman, "Generation alpha at the intersection of technology, play and motivation," Proceedings of the Annual Hawaii International Conference on System Sciences, pp. 82-90, 2014.

[14] J. Piaget, Constructivism (learning theory) Constructivist theory, History, 2016.

[15] C. C. Bonwell, and J. A. Eison, "Active Learning: Creating Excitement in the Classroom. ASHE-ERIC Higher Education Reports," ERIC Clearinghouse on Higher Education, Washington, DC: The George Washington University, pp. 1-121, 1991.

[16] C. Brame, "Active Learning," Vanderbilt University Center for Teaching, 2016. [Online]. Available: https://cft.vanderbilt.edu/active-learning/. [Accessed: June 2020].

[17] A. Özgür, S. Lemaignan, W. Johal, M. Beltran, M. Briod, L. Pereyre, and P. Dillenbourg, "Cellulo: Versatile Handheld Robots for Education," Proceedings of the 2017 ACM/IEEE International Conference on Human-Robot Interaction - HRI '17, pp. 119-127, 2017.

[18] D. Conti, S. Di Nuovo, S. Buono, and A. Di Nuovo, "Robots in Education and Care of Children with Developmental Disabilities: A Study on Acceptance by Experienced and Future Professionals," International Journal of Social Robotics, vol. 9, no. 1, pp. 51-62, 2017. [Online].

[19] L. Armesto, P. Fuentes-Durá, and Perry, D, "Low-cost Printable Robots in Education," Journal of Intelligent \& Robotic Systems, vol. 81, no. 1, pp. 5-24, 2016.

[20] J. M. Angel-Fernandez, and M. Vincze, "Determining the effect of programming language in educational robotic activities," in RO-MAN 2017 - 26th IEEE International Symposium on 
Stephanus Mberema Kangungu, Maizatul Hayati Mohamad Yatim.

Teaching Programming Using the Robot-Based Learning Approach.

International Journal of Artificial Intelligence, vol. 7, no. 2, pp. 22-28, December 2020. DOI: 10.36079/lamintang.ijai-0702.145

Robot and Human Interactive Communication, Institute of Electrical and Electronics Engineers Inc, pp. 658-663, 2017.

[21] K.-Y. Y Chin, Z.-W. W Hong, and Y.-L. L. Chen, "Impact of Using an Educational RobotBased Learning System on Students' Motivation in Elementary Education," IEEE Transactions on Learning Technologies, vol. 7, no. 4, pp. 333-345, 2014. 